\title{
The maturing of positive psychology and the emergence of PP 2.0: A book review of Positive Psychology (3rd ed.) by William Compton and Edward Hoffman
}

\author{
Paul T. P. Wong
}

\begin{abstract}
Compton and Hoffman's third edition of Positive Psychology: The Science of Happiness and Flourishing is commended for advocating an inclusive positive psychology that not only honours the rich humanistic heritage and the major contributions from mainstream psychology, but also recognizes the two emerging trends within what has become known as PP 2.0. The first is the recognition that suffering and vulnerability provide the foundation for building a solid existential positive psychology of flourishing that can endure the inevitable vicissitudes of life. The second trend is the importance of indigenous positive psychology, especially Eastern psychological systems that offer viable insights and hypotheses about the nature of the self and ultimate happiness.
\end{abstract}

\section{Introduction}

Any book review reflects the reviewer's own scholarship and perspective. I want to state right at the outset that my view on positive psychology (PP) has been shaped by my experience of suffering (see Wong, 2019a), which demands a different kind of PP to that which characterises the mainstream of the field, and which has come to be known as Second Wave Positive Psychology (PP 2.0). Therefore, it is inevitable that in this book review, my focus is on how this textbook relates to the important new developments in PP 2.0, which may offer effective ways to help people who are suffering survive and thrive. My hope that this review will expand the horizon for future PP research and intervention.

The two authors of this textbook have a combined history of 80 years of research and teaching on positive mental health and wellbeing. This rich history is clearly reflected in the breadth and depth of their coverage, especially the older humanistic literature and the later developments in indigenous psychology as well as PP 2.0. 
This new edition has 503 pages, in contrast to its earlier edition which had only 381 pages. With approximately 400 new references and many new topics, this textbook represents the most balanced and comprehensive treatment to date of the different trends under the umbrella of PP. It of course covers the traditional topics of Introductory Positive Psychology (Peterson, 2006; Snyder, Lopez \& Pedrotti, 2014). However, what makes Compton \& Hoffman (2019) different from many other such books is its in-depth attempts to integrate research from the humanistic tradition. As they write, "Today, the differences between positive psychology and humanistic psychology are diminishing" (p. 23). I too have argued that even the remaining differences in philosophical assumptions between the two schools will disappear once most scholars in PP accept the value of taking a more holistic and integrative approach towards complex human issues (Wong \& Roy, 2017).

\section{Contribution to the Positive Psychology of Suffering}

Another uniqueness of the book is that Compton and Hoffman (2019) have devoted many of the pages to integrating the positive psychology of human suffering. More than a decade ago, Snyder and Lopez (2007) wrote in their seminal textbook on PP:

"Although we explore the positive, we emphasize that this half is no more the entire story than is the negative side. Future psychologists must develop an inclusive approach that examine both the weakness and the strengths of people, as well as the stressors and the resources in the environment. That approach would be the most comprehensive and valid." (p. 9)

To a large degree, Snyder and Lopez's (2007) wish has been realized in the present textbook by Compton and Hoffman. Ivtzan, Lomas, Hefferon, and Worth (2015) produced the first major textbook exploring the 'dark' side of life and its important role in our positive functioning and transformation as human beings. Here Compton and Hoffman (2019) go a one step further by emphasizing the necessity of integrating human suffering as the basis for wellbeing, meaning, and resilience.

For example, on page 172, they cite Dunn's (1961) research that high-level wellness depends on a combination of living a meaningful live and coping with challenging environments. Similarly, after devoting many pages to posttraumatic growth, they cite Kramer's (2000) research on the wisdom of being open to both positive and negative experiences and grappling with difficult existential life issues, a process that helps transform negative experiences into life-affirming ones (p. 267).

Their coverage of the topic of suffering encompasses Rollo May's emphasis on existential anxiety and the power of the daimonic, Frankl's meaning of suffering, Killam's (2015) review of posttraumatic growth, Cowen and Kilmer's (2002) article challenging the possibility of obtaining stable wellbeing by neglecting fear and death anxiety, and Kaiser's (2009) book questioning the desirability of focusing only on strengths. 
They also introduce Shmotkin's (2005) comprehensive model which assumes that "we all encounter a potentially threatening world, our sense of subjective wellbeing is designed partially to help protect us from the impact of anxiety, worry, and fear." (p. 382) It is worth noting that Shmotkin's theory was influenced by terror management theory's postulate that we are affected by our unconscious fear of death.

In spite of the above, PP has tended to be largely ambivalent towards suffering. On the one hand, many PP documents emphasize that the field does care about repairing what is wrong or broken with people. However, in practice, its research agenda and publications rarely test the possibility that human suffering can be a portal for happiness and strength. Seligman (2003), for example, asked, "Does suffering trump happiness?" By raising this question, he is of course acknowledging that people are naturally concerned about suffering. In response, without directly answering it, he wrote:

"I am often asked two disturbing and profound questions about the place of happiness in a troubled world. In a world of war and hate and famine, how can I advocate that psychology investigate happiness? Suffering has first call on our sympathy, on our dollars, and on our brainpower. Only when these nightmares are stilled should we turn our attention to happiness."

However, one might say that Seligman himself does not agree with the sentiment expressed in the paragraphs. He would seem to believe that just as clinical psychology can make people less unhappy, PP can make people happier, and these are separate endeavours, each worthy of their place in psychology (Seligman, Steen, Park, \& Peterson, 2005). That said, more recently there have been efforts to bring a PP perspective to bear on clinical contexts, in the form of positive clinical psychology (Peterson \& Seligman, 2003) or positive psychotherapy (Rashid \& Seligman, 2018), aiming to apply strength-enhancing interventions in clinical populations. In that respect, Seligman (2003) concludes:

"But most of Positive Psychology is for all of us, troubled or untroubled, privileged or in privation, suffering or carefree. The pleasures of a good conversation, the strength of gratitude, the benefits of kindness or wisdom or spirituality or humility, the search for meaning and the antidote to "fidgeting until we die" are the birthrights of us all."

Thus, Seligman's answer to human suffering appears to be to primarily focus on what makes us happy, thereby not only repairing what is damaged, but also bringing out what is good and right with all people, "suffering or free". However, this assumption has not gone unchallenged. For instance, Yakushko (2019) argues that the darker aspects of human existence - suffering and harm in its various forms - cannot necessarily be eradicated by focusing on the positive.

In contrast, PP 2.0 may be considered the positive psychology of suffering; it takes suffering as the starting point or foundation of existence, and then explores how we can transform suffering 
into wellbeing and strengths. According to this integrative view, a focus on positive emotions and traits, without addressing people's inner demons and the dark side of life, is limited in its potential; it's preferable to develop a dialectical approach of integrating negatives and positives in achieving optimal wellbeing. Thus, the basic tenet of PP 2.0 is that flourishing can be achieved only through a foundational integration of human suffering. This reorientation is a fundamental shift in how PP is conceived and practised, hence it being marked as a new 'wave' within the field (Wong, 2019).

A similar perspective can also be found in Fowers, Richardson, and Slife (2017). They provided compelling research evidence and case studies to support their dialectical view that the best pathway to flourishing is to embrace and integrate suffering as an essential part of our journey towards healing and personal growth. They presented their "breathless optimism" as a corrective for the current mainstreamof scholarship on PP.

This of course does not mean we should glorify suffering. Rather, we need to understand that suffering can imbue life with significance in many ways. It may trigger our search for meaning and meaning making, thus leading us to different priorities and paths. It may increase our compassion for others who suffer. Finally, suffering often occurs in life domains of importance to us:

\begin{abstract}
"How can people thrive, given dependency, the complexity of life human limits, and unavoidable suffering? We have written this book to answer the question. How to flourish remain the theme of positive psychology, but there can be no adequate answer with addressing the question of how to integrate the unavoidable suffering. We show not only it is possible to flourish as imperfect beings, but also that human frailty actually central to living well." (Fowers et al., p. 3)
\end{abstract}

This dialectical framework has guided all my research on wellbeing. Examples include the positive psychology of transforming stress into competence and resilience (Wong, Wong, \& Scott, 2006); the positive psychology of transforming the terror of death into death acceptance and meaning in life (Wong \& Tomer, 2011); the deep-and-wide hypothesis in giftedness and creativity (Wong \& Worth, 2017); the positive psychology of transforming despair into tragic optimism (Wong, 2009); and positive aging (Wong, 1989). All these examples illustrate the power of positive interventions based on the dialectical mindset.

At long last, Compton and Hoffman have addressed many of the above themes, which tended to be overlooked by the PP community when these topics were first introduced as new frontiers of the field. They also point how these insights can be found in various spiritual and wisdom traditions. For instance, a central concern of Buddhist psychology is reducing suffering through mindful meditation as the pathway to ultimate happiness (Hanh, 2017). Christian psychology holds a similar approach of achieving happiness through resolving the problem of evils and suffering. Similarly, modern psychologists, from Frankl (1985) to Peterson (2018), have found that a meaningful life is built on a foundation of suffering. Personally, it has been through my 
struggles to survive the horrors of Japanese occupation, cancer, betrayal, discrimination, and the Christian faith that I have discovered the power of PP 2.0.

Unfortunately, the concept of finding meaning, strength, and happiness through suffering is often still dismissed by some leading figures in the field. As a case in point, I have personally been frequently told that my view on suffering is "pessimistic and unscientific," and that empirical evidence is needed to support my claim that life is full of suffering. Do we really need empirical evidence from psychology labs to prove that life is full of suffering, when suffering can be seen as a universal phenomenon experienced by every human being? Such resistance to suffering hinders PP from exploring the new frontiers offered by the paradoxical and dialectical mindset, as illustrated by Frankl's concept of tragic optimism for instance (Wong, 2009).

Therefore, it behooves all those in the field to ponder the wisdom of Gandhi- "To rejoice in happiness is to invite misery. Real happiness springs from sorrow and suffering" - that is the paradoxical truth of PP 2.0. Authors of the present textbook deserve commendation for having included suffering as a legitimate topic for PP and repeatedly warning against doing research only on what is positive and desirable. My only critique is that it did not introduce Flower et al.'s recent publication (2017), although it made several references to Flower's earlier work.

\title{
3. Contribution to Indigenous Positive Psychology
}

In the words of Compton and Hoffman (2019):

\begin{abstract}
"Among the frequent criticisms of positive psychology (and Western psychology in general) has been that it over-relies on North American and European research participants. It is indeed clear that some research findings are attributed universal significances when they actually apply only within a specific culture at a specific historical moment." (p. 391)
\end{abstract}

They go on to document not only ethnic differences within the West, but also cultural differences between the East and West. Compton and Hoffman (2019) also point out:

"When Eastern psychological systems are understood properly, they offer viable insights on well-being, the nature of emotion, the elements of personality and how to change behavior in positive ways... A variety of hypotheses about the nature of the self and ultimate happiness are available from Eastern psychology, and relatively few psychologists in the West attempt to tap into this valuable resource." (p. 392)

It is unscientific to dismiss Eastern ideas and Eastern indigenous psychology without giving these serious consideration. Indeed, of the main tenets of PP 2.0 is the dialectical principle, which is associated with Eastern philosophical traditions such as Taoism.

Figure 1. A dialectical model of mature happiness. 


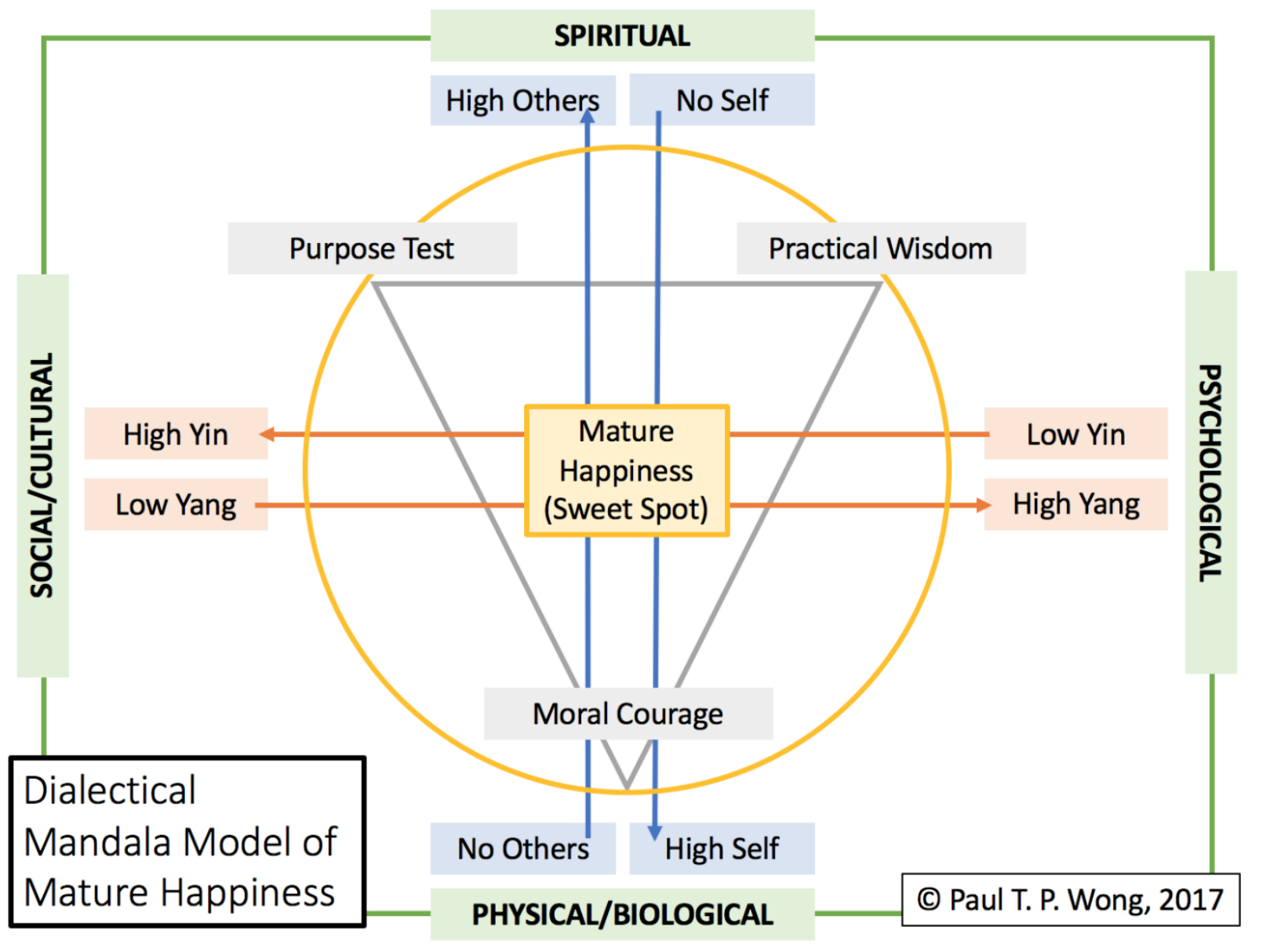

From an Asian philosophical perspective, everything exists in polarity. The dialectical principle of interaction between yin-yang, as shown in Figure 1 and explained in Wong (2011), is a seen as a universal principle underlying all phenomena, including mental health. This dialectical perspective is reflected in modern scholarship too, such as Lomas and Ivtzan's (2016) dialectical analysis of wellbeing, Peterson's (2018) dialectical analysis of meaningful striving through having one foot in security and another foot in order, and Wang, Wong, Yeh, and Wang's (2018) meaningful life and dialectical coping. Similarly, the dialogue between PP 2.0 and Buddhism is an example of how to integrate the East with the West (Bliss and Wisdom Global Website, 2017).

Wong's (2012) dual-systems model crystalizes the practical wisdom of navigating an adaptive balance between the dynamic interactions of opposing forces to optimize wellbeing in different contexts. Thus, depending on the situation, one needs to manage the tension of various dialectics, such as getting ahead vs. getting along, trust vs. distrust, engagement vs. disengagement, and happiness vs. sorrow. Such dialectic thinking will contribute to one's flexibility in adapting to life's many challenges.

\section{The Future of Positive Psychology}

Compton and Hoffman (2019) offer a broad and optimistic vision of a truly balanced, integrative PP: 
"Researchers in positive psychology will be kept busy for some time to come exploring personality, lived environments, the interpretation of life events, the various criteria for well-being, and interventions to enhance well-being in an era of new challenges and opportunities for humanity." (p. 394)

In terms of the future of $\mathrm{PP}$, at least two important potential avenues of development are linked to PP 2.0: (a) the integration of negatives and positives and (b) the integration of mainstream and indigenous psychology. Such an integrative PP will open new opportunities for research and interventions in the global wellbeing movement.

Other developmental paths include inclusivity and integration with regard to epistemology and methodology. For instance, reinforcing their appeal for an integrative PP, the authors of the textbook cite Hefferon, Ashfield, Waters, and Synard (2017):

"We aspire towards more balanced, diverse and inclusive positive psychological research design where one approach is not privileged over the other. We further advocate for researchers to start exploring and engaging in reach across the epistemological spectrum as both quantitative and qualitative approaches can add a piece to the Wellbeing/Flourishing puzzle and have value in their own right." (p. 217)

Similarly, citing Kristjánsson (2010), Compton and Hoffman (2019, p. 391) emphasize that it is difficult to remove values completely from the scientific study of wellbeing. Therefore, researchers who advocate positivist and naturalist values should not automatically dismiss research findings based on transcendental values. Furthermore, they also suggest that PP needs to "specify more precisely what kinds of ideals for well-being or what types of happiness are being pursued through research. None of these issues should negate the scientific enterprise in any way."

Ideally, science is the final arbitrator among alternative hypotheses. However, this has to be based on science as broadly defined. Life is complicated, and people are complex. If we believe in the unity of human nature but also that there are different expressions in different cultures, we really need to broaden our approach to research as suggested by the authors:

"Although [science] brings a necessary and welcome addition to the study of wellbeing, science is a useful tool that may work best when used with other tools that examine the human condition... The study of individual and group well-being is particularly suited to collaboration among a diversity of scientists, scholars, educators, and other practitioners around the world." (Compton \& Hoffman, 2019, p. 393-394)

Following Rathunde (2001), they suggest that we go back to William James, John Dewey, and Abraham Maslow. Thus, what was old becomes new again through new theoretical lenses and 
research methodologies. For example, PP 2.0 focuses on contributing factors, the dialectical processes of adaptation, and outcome measures of people's wellbeing and optimism in their darkest hours. It fills a void in existential PP by drawing attention to the suffering masses. PP 2.0 also advocates research to measure the interactions between opposing forces and objective indexes of wellbeing in concrete contexts, including both normal circumstances and aversive situations.

Only empirical research will decide whether, in circumstances of adversity, PP 2.0's approach of seeking the mature happiness of inner peace by engaging with weaknesses will compare to the efficacy of the conventional happiness-enhancing interventions of PP. Research may also decide whether it is more effective for wellbeing to address vulnerabilities and one's dark side, as advocated by PP 2.0, compared to the focus on positive emotions and positive traits as advocated by mainstream PP.

Nevertheless, scholarship is emerging that do give support to the PP 2.0 perspective, such as Kaplan and Kaiser's book (2013) Fear your strengths: What You are Best at Could Be Your Biggest Problem, and Feldman and Kravetz's (2015) Supersurvivors: The Surprising Link Between Suffering and Success. Likewise, a recent study by Kaufman, Yaden, Hyde, and Tsukayama (2019) showed the value of looking at both positive and negative personality traits in wellbeing. They found that the Light Triad Scale (LTS) predicted satisfaction and a wide range of growth-oriented outcomes, while the Dark Triad was negatively associated with life satisfaction and growth-oriented outcomes. Future research will determine whether the dialectical mindset of accepting the dark side of life is more adaptive than the dichromatic mindset of avoiding it in promoting the mission of "positive, adaptive, healthy and admirable qualities of humanity" in different contexts (Compton \& Hoffman, 2019, p. 394).

\section{Conclusion}

Compton and Hoffman (2019) end the book with the life motto of Compton's mother, which in part says:

Throughout the coming years, may you have:

Enough happiness to keep you sweet,

Enough trials to keep you strong,

Enough sorrow to keep you human,

Enough hope to keep you happy,

Enough failure to keep you humble,

Enough success to keep you eager,

Enough friends to give you comfort,

Enough wealth to meet your needs,

Enough faith to banish depression,

Enough determinations to make each day better than yesterday. (pp. 394-395) 
This list sounds like a perfect example of the good life from the perspective of PP 2.0-a life of moderation and balance through integrating negative and positive experiences. Such a good life demands the responsibility to do the right thing each day, and the discipline to overcome adversities with the spiritual triad of faith, love, and meaning. In short, Compton mother's life is a demonstration that a good life is achievable only through successfully integrating opposing dialectical forces (Wong, 2011). As Compton and Hoffman (2019, p. 410) put it:

Research findings from positive psychology are intended to supplement, not remotely to replace, what is known about human suffering, weakness, and disorder. The intent is to have a more complete and balanced scientific understanding of the human experience-the peaks, the valleys, and everything in between. We believe that a complete science and a complete practice of psychology would include an understanding of suffering and happiness, as well as their interaction, and validated interventions that both relieve suffering and increase happiness - two separable endeavors."

After 20 years of PP research, the present book shows us that by following the Hegelian dialectical logic, clinical psychology (thesis) and positive psychology (antithesis) are moving into the stage of synthesis as evident in PP 2.0. Thus, suffering and weakness can be seen as a foundation for building a solid existential PP of flourishing that can endure the inevitable vicissitudes of life. Compton and Hoffman's (2019) book shows us that the most powerful tool in any psychologist's toolbox is neither the skill to repair brokenness, nor the skill to increase strength, but the skill to transform brokenness into strength, thus integrating healing with flourishing.

It has been a validating experience for me to read this textbook, because the authors happen to share the same orientation towards PP as myself. They not only honour the rich humanistic heritage and the major contributions from mainstream psychology, but also recognize the two emerging trends of PP 2.0, namely, the PP of suffering and indigenous PP. Compton and Hoffman's sweeping, bold vision of inclusiveness, diversity, and integration for the future of PP show us how we can build a better life for the self and for society by confronting and transforming the dark side of life as the foundation for human flourishing. Furthermore, it was written in a clear and easy to understand style, and also includes a Personal Exploration Section for students to engage with the concepts in a personally meaningful way. As such, I highly recommend Compton and Hoffman's (2019) book as a textbook for positive psychology.

\section{Author}

Paul Wong

Trent University, Peterborough, Canada

drpaulwong@gmail.com

\section{Publishing Timeline}

Received 26 March 2019

Accepted 13 January 2020 
Published 1 February 2020

\section{References}

Bliss and Wisdom Global Website. (2017, October 24). Positive Psychology 2.0 and Dharma-Talk between Dr. Paul T. P. Wong and Bliss \& Wisdom Buddhist Sangha community. Bliss and Wisdom Global Website. https://www.blisswisdom.org/events/e/1981-40532

Compton, W. C., \& Hoffman, E. L. (2019). Positive psychology: The science of happiness and flourishing (3rd ed.). Thousand Oaks, CA: Sage.

Cowen, E. L., \& Kilmer, R. P. (2002). "Positive psychology": Some plusses and some open issues. Journal of Community Psychology, 30(4), 449-460. https://doi.org/10.1002/jcop.10014

Dunn, H. (1961). High-level wellness. Arlington, VA: Beatty.

Feldman, D. B., \& Kravetz, L. D. (2015). Supersurvivors: The surprising link between suffering and success. New York, NY: HarperWave.

Frankl, V. E. (1985). Man's search for meaning. New York, NY: Simon \& Schuster.

Hanh, T. N. (2017). How to fight (Mindfulness essentials). Berkeley, CA: Parallax Press.

Hefferon, K., Ashfield, A., Waters, L., \& Synard, J. (2017). Understanding optimal human functioningThe 'call for qual' in exploring human flourishing and well-being. The Journal of Positive Psychology, 12(3), 211-219. https://doi.org/10.1080/17439760.2016.1225120

Ivtzan, I., Lomas, T., Hefferon, K., \& Worth, P. (2015). Second wave positive psychology: Embracing the dark side of life. New York, NY: Routledge.

Kaiser, R. (Ed.). (2009). The perils of accentuating the positive. Oklahoma City, OK: Hogan.

Kaplan, R. E., \& Kaiser, R. B. (2013). Fear your strengths: What you are best at could be your biggest problem. San Francisco, CA: Berrett-Koehler.

Kaufman, S. B., Yaden, D. B., Hyde, E., \& Tsukayama, E. (2019). The light vs. dark triad of personality: Contrasting two very different profiles of human nature. Frontiers in Psychology, 10, 467. https://doi.org/10.3389/fpsyg.2019.00467

Killam, K. (2015, December 15). How to find meaning in suffering: Useful insights from research on "post-traumatic growth". Scientific American. https://www.scientificamerican.com/article/how-tofind-meaning-in-suffering/

Kramer, D. A. (2000). Wisdom as a classical source of human strength: Conceptualization and empirical inquiry. Journal of Social and Clinical Psychology, 19(1), 83-101. https://doi.org/10.1521/jscp.2000.19.1.83

Kristjánsson, K. (2010). Positive psychology, happiness, and virtue: The troublesome conceptual issues. Review of general psychology, 14(4), 296-310. https://doi.org/10.1037/a0020781

Lomas, T., \& Ivtzan, I. (2016). Second wave positive psychology: Exploring the positive-negative dialectics of wellbeing. Journal of Happiness Studies, 17(4), 1753-1768. https://doi.org/10.1007/s10902-015-9668-y

Peterson, C. (2006). A Primer in Positive Psychology. New York, NY: Oxford University Press.

Peterson, C., \& Seligman, M. E. P. (2003). Character strengths before and after September 11. Psychological Science, 14(4), 381-384. https://doi.org/10.1111/1467-9280.24482

Peterson, J. B. (2018). 12 rules for life: An antidote to chaos. Toronto, ON: Random House Canada.

Rashid, T., \& Seligman, M. E. P. (2018). Positive psychotherapy: Clinician manual. New York, NY: Oxford University Press.

Rathunde, K. (2001). Toward a psychology of optimal human functioning: What positive psychology can learn from the "experiential turns" of James, Dewey, and Maslow. Journal of Humanistic Psychology, 41(1), 135-153. https://doi.org/10.1177/0022167801411008

Seligman, M. E. P. (2002). Authentic happiness: Using the new positive psychology to realize your potential for lasting fulfillment. New York, NY: Free Press.

Seligman, M. E. P. (2003). Does suffering trump happiness? Authentic Happiness. Retrieved from https://www.authentichappiness.sas.upenn.edu/newsletters/authentichappiness/suffering

Seligman, M. E. P. (2011). Flourish: A visionary new understanding of happiness and well-being. New York, NY: Free Press. 
Seligman, M. E. P., Steen, T. A., Park, N., \& Peterson, C. (2005). Positive psychology progress: Empirical validation of interventions. American Psychologist, 60(5), 410-421. https://doi.org/10.1037/0003066X.60.5.410

Shmotkin, D. (2005). Happiness in the face of adversity: Reformulating the dynamic and modular bases of subjective well-being. Review of General Psychology, 9(4), 291-325. https://doi.org/10.1037/10892680.9.4.291

Snyder, C. R., \& Lopez, S. J. (2007). Positive psychology: The scientific and practical explorations of human strengths. Thousand Oaks, CA: Sage.

Snyder, C. R., Lopez, S. J., Pedrotti, J. (2014) Positive Psychology: The Scientific and Practical Explorations of Human Strengths. Thousand Oaks, CA: Sage.

Wang, S.-Y., Wong, Y. J., Yeh, K.-H., \& Wang, L. (2018). What makes a meaningful life? Examining the effects of interpersonal harmony, dialectical coping, and nonattachment. Asian Journal of Social Psychology, 21(3), 198-204. https://doi.org/10.1111/ajsp.12212

Wong, P. T. P. (1989). Personal meaning and successful aging. Canadian Psychology, 30(3), 516-525. https://doi.org/10.1037/h0079829

Wong, P. T. P. (2009). Viktor Frankl: Prophet of hope for the 21st century. In A. Batthyány, \& J. Levinson (Eds.), Existential psychotherapy of meaning: Handbook of logotherapy and existential analysis. Phoenix, AZ: Zeig, Tucker \& Theisen.

Wong, P. T. P. (2011). Positive psychology 2.0: Towards a balanced interactive model of the good life. Canadian Psychology, 52(2), 69-81. https://doi.org/10.1037/a0022511

Wong, P. T. P. (2019a). Why and How I Developed the Positive Psychology of Suffering. Dr. Paul T. P. Wong. Retrieved from http://www.drpaulwong.com/why-and-how-i-developed-the-positivepsychology-of-suffering/

Wong, P. T. P. (2019b). Second wave positive psychology's (PP 2.0) contribution to counselling psychology. Counselling Psychology Quarterly [Special Issue]. https://doi.org/10.1080/09515070.2019.1671320

Wong, P. T. P. (2019c). A Clinical Case Based On Meaning Therapy And PP 2.0. Dr. Paul T. P. Wong. Retrieved from http://www.drpaulwong.com/a-clinical-case-based-on-meaning-therapy-and-pp2-0/

Wong, P. T. P., \& Roy, S. (2017). Critique of positive psychology and positive interventions. In N. J. L. Brown, T. Lomas, \& F. J. Eiroa-Orosa (Eds.), The Routledge international handbook of critical positive psychology. London, England: Routledge.

Wong, P. T. P., \& Tomer, A. (2011). Beyond terror and denial: The positive psychology of death acceptance. Death Studies, 35(2), 99-106. https://doi.org/10.1080/07481187.2011.535377

Wong, P. T. P., \& Worth, P. (2017). The deep-and-wide hypothesis in giftedness and creativity [Special issue]. Psychology and Education, 54(3/4).

Wong, P. T. P., Wong, L. C. J., \& Scott, C. (2006). Beyond stress and coping: The positive psychology of transformation. In P. T. P. Wong, \& L. C. J. Wong (Eds.), Handbook of multicultural perspectives on stress and coping (pp. 1-26). New York, NY: Springer.

Yakushko, O. (2019). Scientific Pollyannaism: From inquisition to positive psychology. Cham, Switzerland: Palgrave Macmillan. 